$\mathbb{T}$ periodica polytechnica

Civil Engineering

$52 / 1(2008) 23+27$

doi: 10.3311/pp.ci.2008-1.03

web: http://www.pp.bme.hu/ci

(c) Periodica Polytechnica 2008

RESEARCH ARTICLE

\section{Analysing automatic satellite image classification in the desert of Sudan}

\author{
András Dénes Ládai / Árpád Barsi
}

Received 2007-12-05

\begin{abstract}
The paper analyses the unsupervised classification method ISODATA. A Landsat ETM image was taken about the Nile region in Sudan, where a Hungarian expedition worked for several months. In the preparation phase of the project, this satellite image was analysed and it has been stated, that the unsupervised classification can fail or get lower thematic accuracy. The paper focuses therefore on the statistical behaviour of the ISODATA technique. Different parameterized clusterings were executed, followed by statistical analysis of the cluster signatures.
\end{abstract}

\section{Keywords}

GIS $\cdot$ thematic classification - object detection · image processing

\section{Acknowledgement}

The authors want to express their thanks to the staff of the Department of Photogrammetry and Geoinformatics, the HUNGIS Foundation, the Mélyépító Foundation, the Peregrinatio BME Foundation and the Az Építố Fejlödésért Foundation for sponsoring the geodetic and geoinformatical works.

\section{András Dénes Ládai}

Department of Photogrammetry and Geoinformatics, BME, Múegyetem rkp. 3. Budapest, H-1521, Hungary

e-mail: alada@mail.bme.hu

\section{Árpád Barsi}

Department of Photogrammetry and Geoinformatics, BME, Múegyetem rkp. 3. Budapest, H-1521, Hungary

\section{Introduction}

The thematic classification of remotely sensed images has long tradition. Different methods were tested to extract surface objects, but the drawbacks of these algorithms also have been described. Although there is a strong expectation in fully automatic image interpretation, the sophisticated analysis of these techniques still fails nowadays. In our paper we present a series of unsupervised classifications (clusterings) including the statistical analyses of the result.

A new dam is under construction on the River Nile in Northern Sudan at the Fourth Cataract. This dam will create an approximately 180 kilometer long reservoir along the river valley. The Sudanese National Corporation for Antiquities and Museums has launched a major international project for missions to make survey and excavations in the particular area before its inundation. The Hungarian team has joined this work with archeologists, Egyptologists, an architect and a surveyor, one of the authors of this paper. Fig. 11 shows the international concession structure with the Hungarian area. The Hungarian expedition's region is $20 \mathrm{~km}$ of the riverbank on the Nile's left side. The project is to explore the complete concession area in two seasons, surveying all historical objects from Stone Age to the end of the Christian Age $\left(13^{\text {th }}-14^{\text {th }}\right.$ century), and to excavate the most important artifacts. The first season was accomplished in February 2006.

The applied satellite imagery was captured by the Landsat ETM system in the $31^{\text {st }}$ of October 2001. Both the $6^{\text {th }}$ thermal infrared and the $8^{\text {th }}$ panchromatic channel were ignored, so the data set has six bands. The geometric resolution of the imagery is $28.5 \mathrm{~m}$. The Hungarian concession area is shown in Fig. 2, the used band combination equals to the natural colour representation (bands 3-2-1).

As it can be seen the region is mostly covered by sandy valleys and desert. The vegetation can be observed only in the area very close to the River Nile. Vegetation indices bring therefore relatively few information, but the mineral and composite indices have also limited use. 


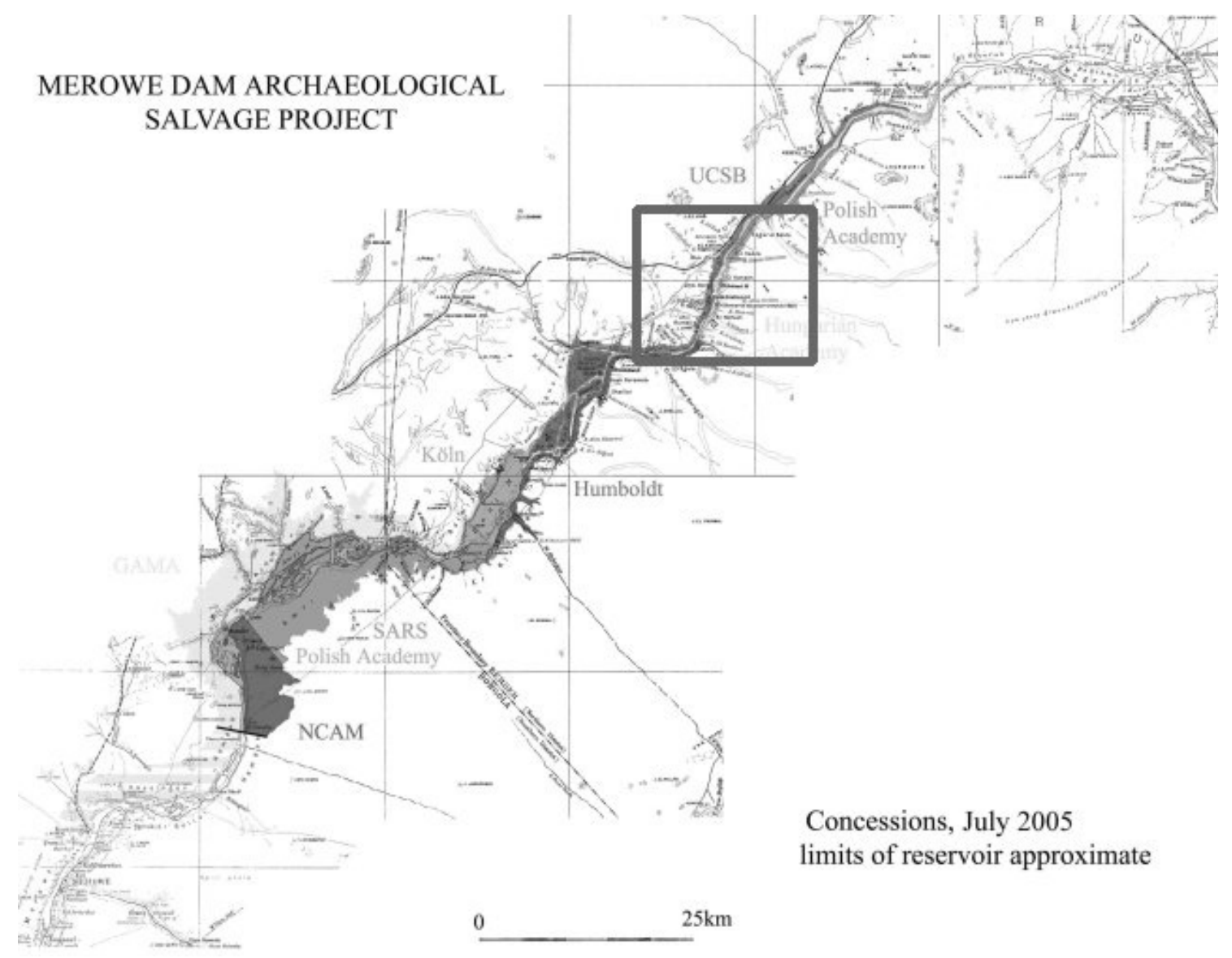

Fig. 1. The Hungarian concession area in the Merowe Dam Salvage Project

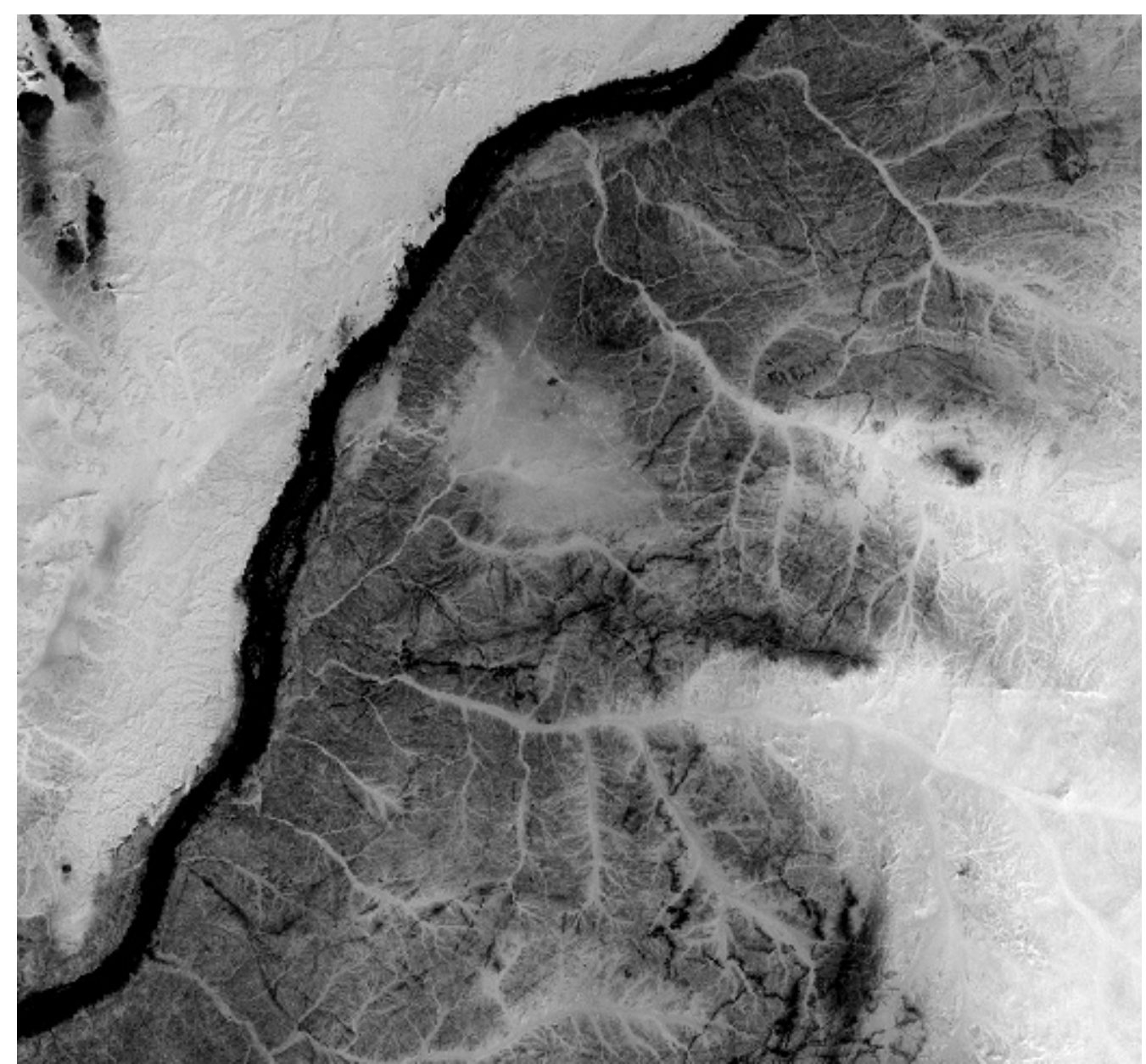

Fig. 2. The natural color visualization of the area of interest (Sudan, Hungarian concession area) 


\section{Isodata classification}

The most known and widely used unsupervised image classification method is the ISODATA (Iterative Self-Organizing Data Analysis Technique A). In the first step the algorithm generates a sample pixel set from the original image, and then given amount of random cluster centers are defined. The clusters are represented by their center points. The iteration contains (a) calculating cluster measures for every pixel and for every cluster, (b) ordering pixels to the cluster having the best cluster measure, (c) computing of the cluster centers using the same cluster "labels". The most used cluster measure is the Euclidean distance, so the ordering means selecting the nearest center. This iteration stops when a given convergence limit or a given number of iteration has been reached. There are versions of algorithms with cluster manipulations: two or more clusters having less distance (than predefined) are merged (cluster fusion), or elongated clusters are split into given number of subclusters, then these will be handled as separate clusters in the next step.

The original algorithm has parameters for the number of iterative steps, convergence threshold, cluster splitting and merging controls. The Erdas Imagine implementation contains only the first two data, extended by the control of the initial cluster building parameters. These initial controls are (a) regularly distributed random cluster centers on the diagonal axis in the intensity space or along the principal axis, or (b) scaling control either by standard deviation or automatically. All of the test runs have used the principal axis with automatic scaling, because the convergence of the iteration is significantly faster.

Every run with maximum 10 iterations and convergence limit of 0.97 produced not only the clustered image, but also a signature file. This contains all cluster information, such as cluster centers, descriptive data about clusters (minimum, maximum, mean, standard deviation) and covariance matrix. Five clusterings were performed with various number of clusters, as it can be seen in the following table:

Tab. 1. Main parameters of the evaluated clusterings

\begin{tabular}{lccc}
\hline Case & Number of clusters & Iteration steps & Final convergence \\
\hline 1 & 2 & 2 & 0.990 \\
2 & 5 & 8 & 0.976 \\
3 & 10 & 10 & 0.966 \\
4 & 20 & 6 & 0.972 \\
5 & 50 & 9 & 0.973 \\
\hline
\end{tabular}

All of the presented cases reached the convergence goal, except Case 3, where after 10 iterations the computation stopped. The final convergence is the measure of clustering stability, because it is a percent-wise measure of unchanging class belongings for the pixels. The number of analysed pixels is 714816 (equal to $876 \times 816$, i.e. the whole image cut-off was analysed), which was the same for all cases.

A typical run for convergence measure can be seen in Fig. 3 . One can notice that the convergence has a small decrease in

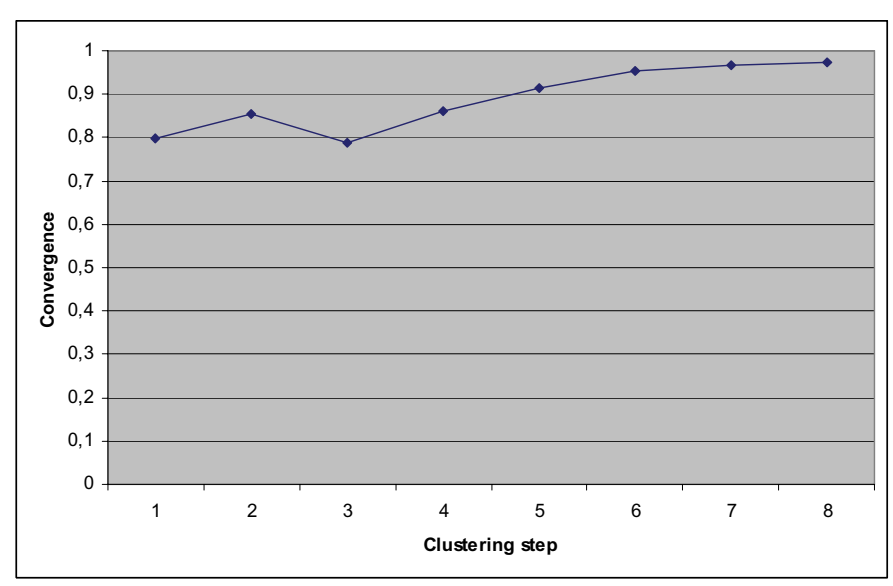

Fig. 3. Increasing convergence measure with 10 clusters

step 3. Such irregularities are present in almost every practical test. The result of the clustering is presented in Fig. 4

\section{Results of the classification analyses}

The five cases of the unsupervised classifications have signature information, which enables further studies. Based on signature information first we calculated the possible combinations between clusters, and then computed two separability matrices, which give overview of the stability of clustering. The first matrix is a Euclidean distance matrix having elements between every cluster center pair (Table 2). This information can be useful, when the accuracy of a minimum distance classifier is to be estimated.

Tab. 2. Euclidean distance matrix of the 5 cluster cases

\begin{tabular}{|c|c|c|c|c|c|}
\hline Siqnature Name & 1 & 2 & 3 & 4 & 5 \\
\hline Class 11 & 0 & 109.156 & 150.109 & 195.727 & 230.005 \\
\hline Class 22 & 109.156 & 0 & 43.0716 & 89.4322 & 123.581 \\
\hline Class 33 & 150.109 & 43.0716 & 0 & 46.416 & 80.8823 \\
\hline Class $4 \quad 4$ & 195.727 & 89.4322 & 46.416 & 0 & 34.9753 \\
\hline Class $5 \quad 5$ & 230.005 & 123.581 & 80.8823 & 34.9753 & 0 \\
\hline
\end{tabular}

The second matrix contains the divergence values, which is a measure similar to the Euclidean distance, but refers to the accuracy of the maximum likelihood classifier.

The before mentioned two matrices can be aggregated into a single value, which represents the overall power of separability. In Table 3 the best average Euclidean distances as well as the best average divergence values are shown for all unsupervised cases.

Fig. 5 illustrates the relation between the two separability measures.

The two different separabilities have fully different figures. The linear measure (Euclidean distance) is almost stable; it seems there is not too much effect on the amount of clusters. As opposed to Euclidean distance, the divergence is very sensitive to the number of clusters, because it increases almost exponentially.

Table 3 is extended by the mean number of the pixels in a 


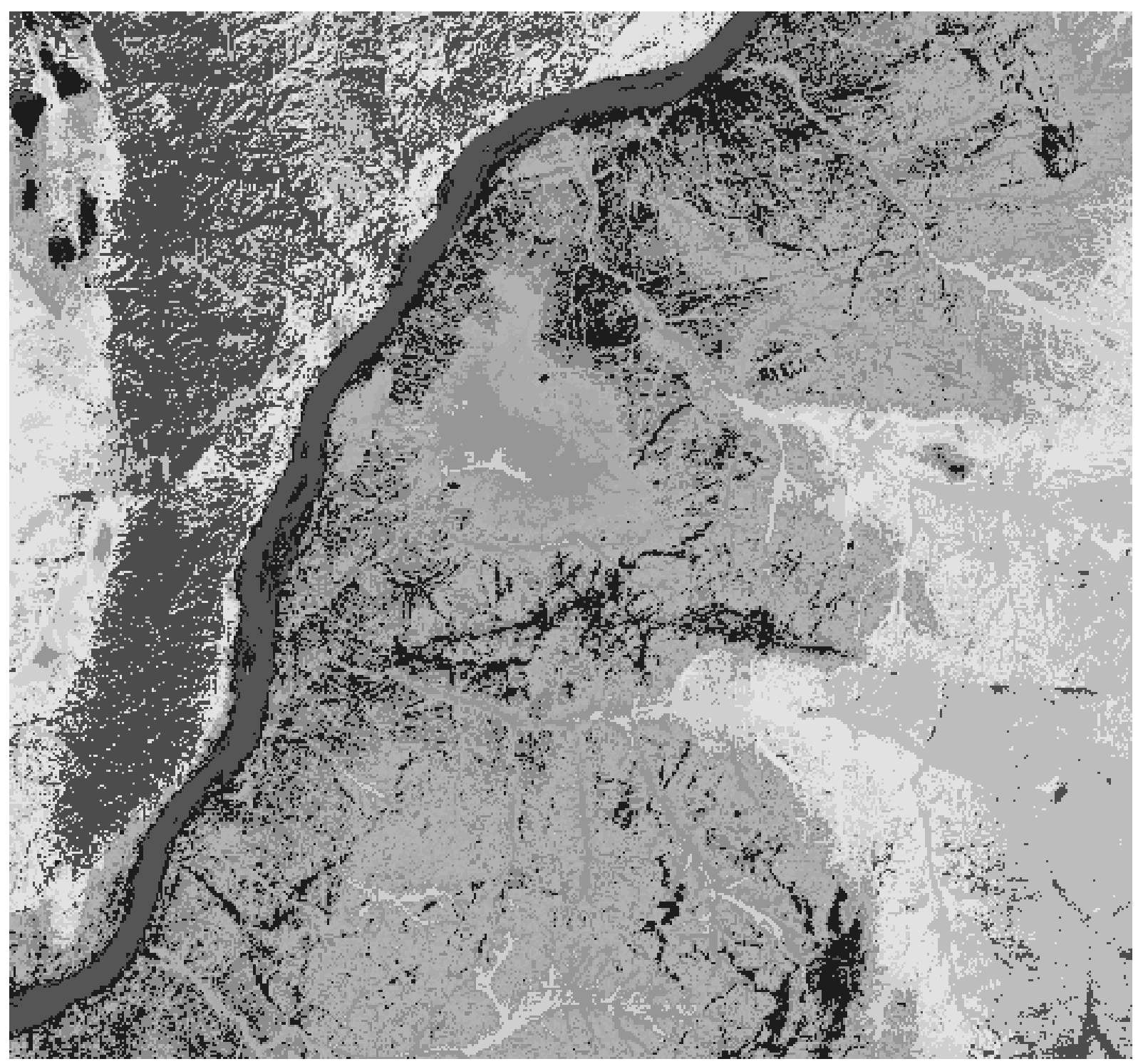

Fig. 4. Cluster map with 10 clusters
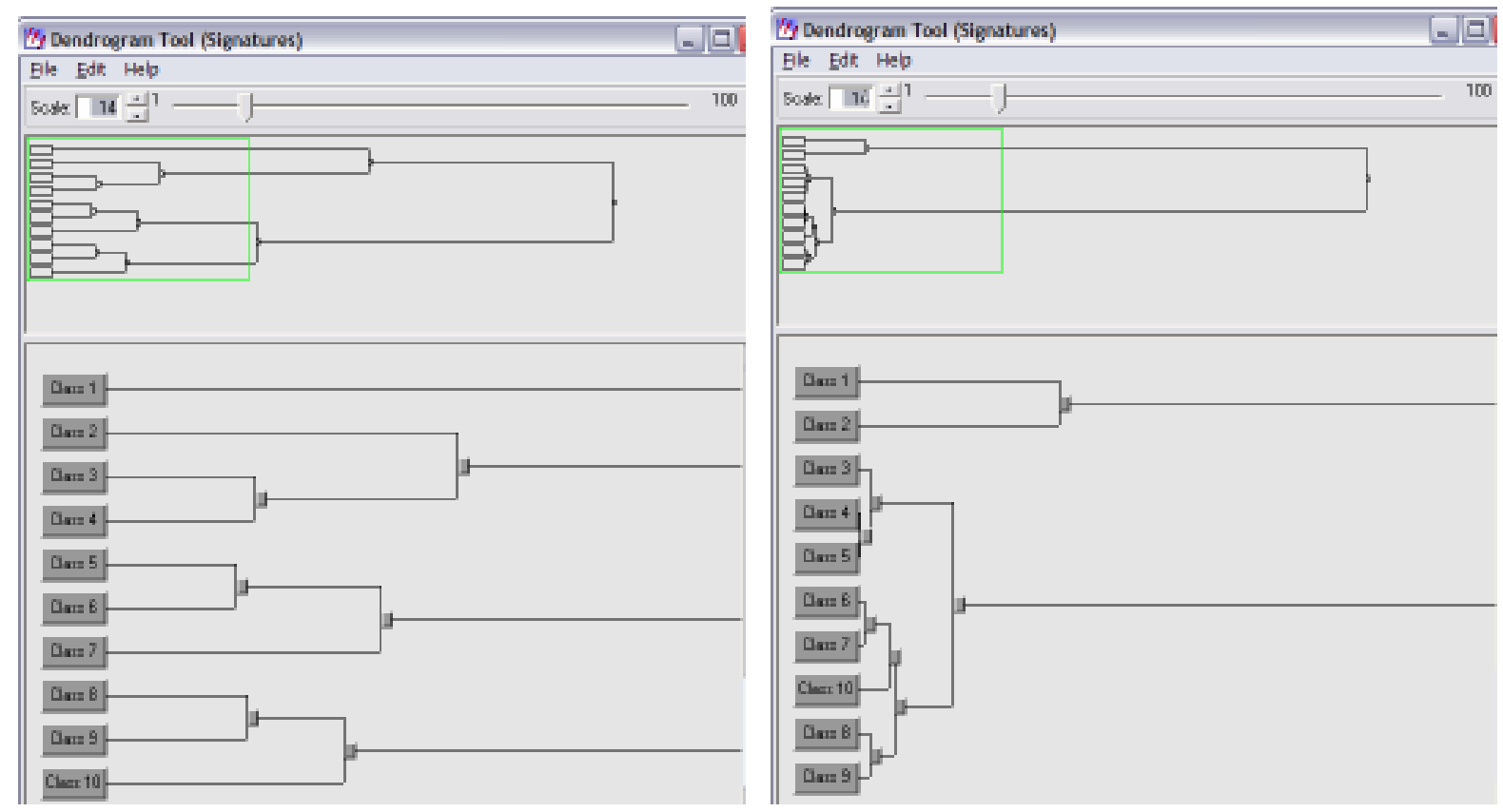

Fig. 6. Dendrograms of Euclidean distance and divergence measures (10 cluster case) 
Tab. 3. Separability statistics about the classification cases

\begin{tabular}{llll}
\hline Case & $\begin{array}{l}\text { Euclidean distance } \\
\text { (best average) }\end{array}$ & $\begin{array}{l}\text { Divergence } \\
\text { (best average) }\end{array}$ & $\begin{array}{l}\text { Mean number } \\
\text { of pixels per } \\
\text { cluster }\end{array}$ \\
\hline 1 & 99.1 & 36.0 & 357408 \\
2 & 110.3 & 168.6 & 142963 \\
3 & 87.9 & 257.7 & 71481 \\
4 & 83.1 & 609.0 & 35740 \\
5 & 87.2 & 1150.7 & 14296 \\
\hline
\end{tabular}

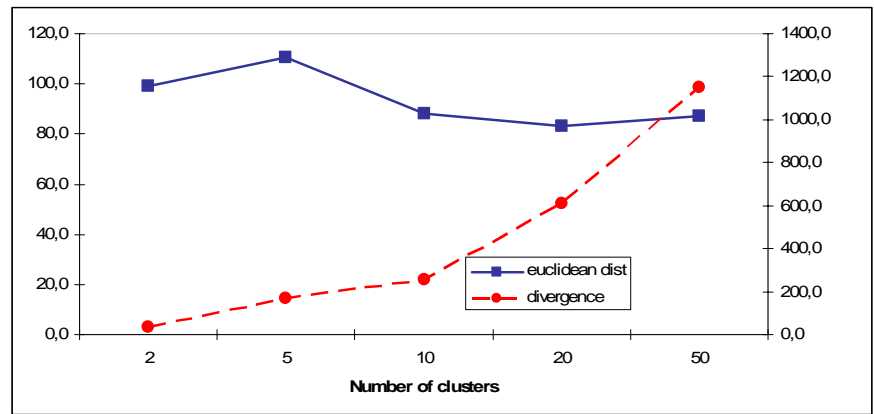

Fig. 5. Euclidean distance and divergence measures for the clusterings

class. It is very easy to notice, that the software orders the pixels into a cluster considering the number of clusters (generally the same amount of pixels in every cluster).

Applying cluster dendograms allows very interesting and informative visualization. It shows the relation among the clusters, because the close neighbours are represented closer. Fig. 6 shows a dendrogram of 10 clusters with both separability measures.

\section{Conclusion}

The unsupervised classification ISODATA is a widely used thematic mapping tool. In case of an expedition area to be mapped, if the cluster-thematic class matching can be achieved, the technique suits for preliminary information source about surface cover. The complexity of the task increases along with the number of clusters and the wide spread hypothesis of "better performance with more clusters" has not become true, since the separability measure does not follow in every case this tendency.

The initial statistical analysis can be continued by involving ground-truth information and supervised classification, as well as tests on other test sites.

\section{References}

1 Duda RO, Hart PE, Stork DG, Pattern Classification, Wiley, New York, 2001.

2 Erdas Imagine Field Guide, Erdas, Atlanta.

3 Erdas Imagine User's Guide, Erdas, Atlanta.

4 Gonzalez RC, Woods RE, Eddins SL, Digital Image Processing Using Matlab, Prentice Hall, 2004. Upper Saddle River.

5 Russ JC, The Image Processing Handbook, CRC Press, 1999. 